\title{
Approach-avoidance conflict behavior as a function of amount and spacing of prior electric shock'
}

\author{
WLLIAM TERRIS AND COKE R. BROWN
}

U.VIVERSITY OF OKLAHOMA

In a factorial study, albino rats were subjected to either six 5-sec. or 30 1-sec. electric shocks for either one or five days and were subsequently tested in an approach-avoidance conflict situation with shock used as the aversive stimulus. The effectiveness of the punishment in the conflict situation did not vary as a function of the spacing or amount of prior electric shock. However, all prior-shock groups were more sensitive to subsequent electric shock than was a no-priorshock control group.

A considerable body of research (e.g., Kurtz \& Walters, 1962; Terris \& Wechkin, 1967; Walters, 1963) indicates that brief experiences with electric shock predispose adult rats to react with greater apparent fear in subsequent encounters with electric shock. More recently, however, Terris \& Enzie (1967) found that adult rats receiving a series of $1-$ sec. electric shocks administered in their home cages over a five-day period were less responsive to subsequent electric shock experienced in a conflict situation than were the noprior-shock controls. This experiment differed from most of the studies which have found sensitization in that Terris and Enzie: (1) administered 301 -sec. shocks rather than six 5-sec. shocks each day; (2) administered the shock for five days rather than for one day; and (3) administered the shock in the home cage rather than in a separate shock box.

The purpose of this experiment was to determine whether the first two procedural differences (i.e., spacing or amount) could account for the discrepant results. Spacing (i.e., 30 1-sec. or six 5-sec. shocks) may be an important factor since the commonly used 5-sec. shock is in reality a series of discrete shocks which occur when the $\mathbf{S}$ momentarily breaks contact with the shock grid. Under these conditions, shock or the internal stimuli associated with shock may become conditioned stimuli for a conditioned emotional response. A series of widely spaced 1-sec. shocks, on the other hand, would not be expected to have the same result since a long time interval between shocks should not produce conditioning. The total amount of shock may also be important since Walters (1963) has found that rats receiving prolonged amounts of electric shock did not show a significant increase in responsiveness to subsequent shock of the same intensity.

Method

The Ss were 38 experimentally naive Holtzman rats approximately 70 days of age at the beginning of the experiment and were housed in individual cages with free access to water throughout the experiment.
The main apparatus consisted of shock cages, an enclosed Plexiglas runway and an electric shock source. The shock cages were similar to the home cages but were lined with plaster board and placed upside down over a brass grid floor. The runway was 36 in. long, 5 in. wide, and 5-7/8 in. deep with a stainless steel grid floor, gray Plexiglas walls and a clear Plexiglas celling. The shock source has been described elsewhere (Terris \& Enzie, 1967).

On Day 1 of the experiment, all Ss were placed on a 22-1/2-hr. food deprivation schedule which was maintained throughout the experiment. Approach training began on Day 7 with all animals receiving three massed approach trials per day through Day 21. Each trial consisted of placing the $S$ into the start box of the runway and recording the time taken for the $S$ to traverse the runway and begin eating (consummatory latency). The $S$ was removed from the goal box and the trial was terminated $15 \mathrm{sec}$. after the $S$ began to eat.

On Days 12-16 all Ss were removed from their home cages and placed into shock cages for $20-\mathrm{min}$. periods. The Ss in two of the groups received shock for all five days with the $\mathrm{Ss}$ in the first group $(\mathrm{N}=8)$ receiving six 5-sec. shocks per day and those in the second group $(\mathrm{N}=8)$ receiving $301-\mathrm{sec}$. shocks per day. An additional two groups of Ss received shock on Day 16 only, with one group receiving six 5-sec. $(N=7)$ and the other $301-\mathrm{sec} .(\mathrm{N}=8)$ electric shocks. The average interval between the 1- and 5-sec. shocks was approximately 34 and $198 \mathrm{sec}$, respectively. A nonshock control group $(\mathrm{N}=6)$ was also placed into the shock boxes but received no shock during Days 12-16. The shock boxes were located in a darkened room and the shocks were administered by the $\mathbf{E}$ from outside the room. Shocks were not administered until $2 \mathrm{~min}$. after the Ss were placed into the shock cages and were terminated at least 30 sec. prior to the end of the 20-min. shock period. The approach training which continued during Days 12-16 occurred approximately 8-10 $\mathrm{hr}$. after the shock box stimulation period.

On Day 22 a .4 mA electric shock of 1-sec. duration was administered immediately following the time when the S's nose touched the food or the food dish. Only one trial per day was given during avoidance testing (i.e., Days 22-26) in which the Ss were allowed a maximum of $5 \mathrm{~min}$. to approach and begin eating the food. The Ss were also allowed a maximum of $5 \mathrm{~min}$. to return to the food after the administration of shock. Only one shock was administered on each trial, and Ss were allowed the 
usual 15 sec. of consummatory time if they returned to the food.

\section{Results and Discussion}

In order to determine whether shock box stimulation had an effect upon subsequent runway performance during approach training, a three-way analysis of variance (ANOVA) was performed on the combined consummatory latencies for the three trials of each day as a function of shock spacing (30 1-sec. or six 5-sec. shocks), shock amount (one day or five days), and days of approach training (Days 16-21). None of the $F$ ratios were significant ( $p>.1$ for each ratio)..$^{2}$ A comparison of the combined prior-shock treatment groups with the control group yielded an insignificant $t$ ratio $(t=.27, d f=$ 35). A one-way ANOVA of the consummatory latencies on Day 22 (1.e., the last approach training trial prior to the introduction of shock into the runway) as a function of the five treatment groups also yielded an insignificant $F$ ratio $(F=1.35, d f=4 / 32)$. A comparison of the combined four prior-shock treatment groups with the control group yielded an insignificant $t$ ratio $(t=.84, d f=35)$.

The analysis of the consummatory latencies during approach training show that there were no differences among the five treatment groups prior to the introduction of shock into the runway and indicates that all groups entered avoidance testing with the same approach strengths.

A three-way ANOVA of reciprocal consummatory latencies during avoidance testing as a function of shock spacing, shock amount, and days of avoidance testing yielded a significant $F$ ratio for days only $\left(F_{\text {Days }}=116.0\right.$, $\mathrm{df}=1 / 108, \mathrm{p}<.001$ ). Other main effects and interactions did not approach significance. However, a comparison of the control group with the combined experimental groups yielded a significant $t$ ratio $(\overline{\mathrm{X}}$ control $=.22, \overline{\mathrm{X}}$ combined experimental $=.39, t=2.27$, df $=35, p<.05$ ) .

An additional measure of responsiveness to shock was the time required to return to the food after the introduction of the first shock into the runway (reconsummatory latency). A two-way ANOVA was performed on the reconsummatory latencies on Day 22 as a function of shock spacing and amount of prior shock stimulation and none of the F ratios approach significance. A comparison of the mean reconsummatory latencies for the control group with the combined prior-shock experimental groups yielded a $t$ which was significant at the .01 level $(\overline{\mathrm{X}}$ control $=10.1 \mathrm{sec} ., \overline{\mathrm{X}}$ combined experimental $=65.6 \mathrm{sec} ., \mathrm{t}=3.99, \mathrm{df}=35$ ).

The results of this study are in agreement with other studies which have found that shock stimulation in- creases responsiveness to subsequent shock but do not indicate that shock spacing or amount of shock can account for the adaptation effects obtained by Terris and Enzie. The obvious procedural difference between the present study and that of Terris and Enzie was the location of the initial shock stimulation. Terris and Enzie administered the shock in the animal's home cage while in the present study, as well as in other studies finding sensitization, animals were removed from their home cages and received the shock in a specially constructed shock box. Most investigators have constructed the shock box so as to minimize the similarity between the shock box and runway situation and typically have found no evidence of stimulus generalization in the analysis of runway performance prior to the introduction of shock into the runway (e.g., Kurtz \& Walters). It is possible, however, that shock box stimulation may establish a conditioned emotional response (CER) to certain cues associated with the shock box. This CER would not be expected to extinguish since the Ss are never placed in the shock box without receiving shock. If the shock box is constructed so as to be physically dissimilar to the runway, little or no generalized CER may be shown by the prior shock Ss when tested in the runway. When shock is introduced into the runway, however, the runway becomes similar to the shock box and the CER would be expected to reappear. In the case of the Ss receiving the shock in the home cage, any CER which is established would be expected to at least partially extinguish, since the Ss are maintained in the home cage for a relatively long time period. In addition, if shock becomes associated with the home cage, a type of counter-conditioning may occur since the home cage is a cue for food, water, and other positive reinforcers.

\section{References}

Kurtz, K., \& Walters, G. The effects of prior fear experiences on an approach-avoidance conflict. J. comp. physiol. Psychol., $1962,55,1075-1078$.

Terris, W., \& Enzie, R. Approach-avoidance conflict behavior as a function of prior electric shock stimulation. Psychon. Sci., 1967, 9 ,

Terris, W., \& Wechkin, S. Approach-avoidance conflict behavior as a function of prior experience with mild or intense electric shock stimulation. Psychon. Sci., 1967, 7, 39-40.

Walters, G. Frequency and intensity of pre-shock experiences as determinants of fearfulness in an approach-avoidance conflict. Canad. J. Psychol., 1963, 17, 412-419.

\section{Netes}

1. This research was supported in part by Public Health Service Grant No. 12052-01. We thank R. Enzie and T. Dunn for their assistance in the data analysis.

2. Probability statements are based upon two-tailed tests. 